\title{
Association between mercury concentrations in blood and hair in methylmercury-exposed subjects at different ages
}

\section{Citation}

Budtz-Jørgensen, Esben, Philippe Grandjean, Poul J Jørgensen, Pál Weihe, and Niels Keiding. 2004. "Association Between Mercury Concentrations in Blood and Hair in MethylmercuryExposed Subjects at Different Ages." Environmental Research 95 (3) (July): 385-393. doi:10.1016/ j.envres.2003.11.001.

\section{Published Version}

doi:10.1016/j.envres.2003.11.001

\section{Permanent link}

http://nrs.harvard.edu/urn-3:HUL.InstRepos:34787239

\section{Terms of Use}

This article was downloaded from Harvard University's DASH repository, and is made available under the terms and conditions applicable to Other Posted Material, as set forth at http:// nrs.harvard.edu/urn-3:HUL.InstRepos:dash.current.terms-of-use\#LAA

\section{Share Your Story}

The Harvard community has made this article openly available.

Please share how this access benefits you. Submit a story.

Accessibility 


\title{
Association between Mercury Concentrations
}

\section{in Blood and Hair in Methylmercury-Exposed Subjects at Different Ages}

\author{
Esben Budtz-Jørgensen, ${ }^{*,+}$ Philippe Grandjean, ${ }^{*, \neq}$ Poul J. Jørgensen, ${ }^{\S}$ \\ Pál Weihe, ${ }^{*}, \#$ Niels Keiding ${ }^{\dagger}$
}

\begin{abstract}
${ }^{*}$ Institute of Public Health, University of Southern Denmark, DK-5000 Odense, Denmark; ${ }^{+}$Department of Biostatistics, Institute of Public Health, University of Copenhagen, DK-2200 Copenhagen, Denmark; ${ }^{\ddagger}$ Department of Environmental Health, Harvard School of Public Health, Boston, MA 02115, USA; ${ }^{\S}$ Institute of Clinical Research, Odense University Hospital, DK-5000 Odense, Denmark; "Faroese Hospital System, FR-100 Tórshavn, Faroe Islands
\end{abstract}

Abstract: Mercury concentrations were measured in paired hair and blood samples from a cohort of about 1000 children examined at birth and at 7 and 14 years of age. The ratio between concentrations in maternal hair (in $\mu \mathrm{g} / \mathrm{g}$ ) and in cord blood $(\mu \mathrm{g} / \mathrm{l}$ ) was approximately 200 , but samples from the children at age 14 years showed a ratio of about 250 . These findings are in accordance with previous data from smaller studies. However, an even higher ratio of about 360 was seen at 7 years of age, suggesting that hair strands at this age retain more mercury. The 95th percentile of the hair-to-blood ratio was between 5 -fold and 9-fold greater than the 5 th percentile. The results were examined in structural equation models to estimate the total imprecision of the individual biomarker results and the possibility that the ratio may not be constant. The hair-to-blood ratio was found to increase at lower mercury concentrations, a tendency that could not be explained by potential confounders, such as alcohol intake or number of amalgam fillings. The total imprecision (coefficient of variation) for the blood determinations averaged about 30\%, thereby substantially exceeding normal laboratory imprecision. Yet, hair-mercury results had an even greater imprecision that suggested that preanalytical factors, such as variable sample characteristics, impacted on the results. These findings are in accordance with other evidence that the cord blood concentration is a better predictor of neurobehavioral toxicity than is the maternal hair concentration. Although practical for field studies and monitoring purposes, hair-mercury concentration results, therefore, need to be calibrated and interpreted in regard to each specific study setting.

Keywords: Biological markers, Dose-response relationship, Laboratory quality, Seafood, Structural equation model 


\section{INTRODUCTION}

The two biomarkers most frequently used to determine individual exposures to methylmercury are the mercury concentrations in scalp hair and in whole blood (Grandjean et al., 1994). The convenience of sampling and storage has made the former parameter advantageous for monitoring and field studies, and the total mercury concentration in hair is thought to reflect the average methylmercury concentrations circulating in the blood (IPCS, 1990; Cernichiari et al., 1995b). Yet, environmental mercury vapor may bind to the hair (Yamaguchi et al., 1975), while hair permanent treatments may remove endogenous mercury from the hair (Yamamoto and Suzuki, 1978; Yasutake et al., 2003). Also, hair color may affect the mercury concentration (Grandjean et al., 2002).

From a toxicological viewpoint, the blood concentration is the appropriate indicator of the absorbed dose and the amount systemically available. Methylmercury binds to hemoglobin, and the high affinity to fetal hemoglobin results in a higher mercury concentration in cord blood than in maternal blood (Tsuchiya et al., 1984; Stern and Smith, 2003). While routine analyses for total mercury concentrations will include inorganic mercury, cord blood mercury is almost entirely on the methylated form, which passes easily through the placenta (Kelman et al., 1982; Tsuchiya et al., 1984; IPCS, 1990).

In comparing results of these two biomarkers, temporal factors must also be considered. Methylmercury is incorporated into the hair during its formation in the hair follicle, but it will take at least a month for the metal content to become detectable in a hair sample cut with scissors close to the scalp (Grandjean, 1984; Suzuki, 1988). Depending on the length of the hair sample, the mercury concentration may reflect exposures that extend far into the past. Still, because the half-life of methylmercury in the body is about 1.5-2 months (Smith and Farris, 1996; Swartout and Rice, 2000), the hair closest to the scalp reflects recent exposures that also contribute to the current blood concentration (Grandjean et al., 2003).

The association between the two exposure biomarkers will depend on the circumstances of individual studies, and, as a result, some prospective cohort studies on developmental methylmercury toxicity have used both biomarkers (Grandjean et al., 1992; Steuerwald et al., 2000). Factor analysis has been used to determine the total imprecision, i.e., laboratory imprecision and all preanalytical variation, of these two biomarkers (Budtz-Jørgensen et al., 2003). The total imprecision of the hair-mercury concentration was found to be almost twice that of the blood determination. This finding is in accordance with the toxicological prediction and empirical observation that the cord-blood mercury concentration is a better predictor of mercury-associated neurobehavioral deficits (Grandjean et al., 1999). However, even the cord blood parameter had a surprising imprecision (expressed by the coefficient of variation, CV) of about $30 \%$. A non-differential error in the biomarker is likely to cause underestimation of the true association with the outcome variables (Carroll, 1998). Adjustment can be made only if the extent of the total imprecision is known.

Translation between studies that have applied different biomarkers requires information about conversion factors. Under reasonably constant conditions of exposure, the human hair-mercury concentrations (in $\mu \mathrm{g} / \mathrm{g}$ ) is thought to average about 250 -fold the wholeblood mercury concentration (in $\mu \mathrm{g} / \mathrm{ml}$ ) (U.S.EPA, 2001). However, concentration ratios expressed as regression coefficients appear to vary somewhat in European and American population groups (Haxton et al., 1979; Phelps et al., 1980; Turner et al., 1980; Sherlock et al., 1982; Akagi, 1998). A limitation of regression analyses is that they do not take into account that both biomarkers are affected by imprecision, and the concentration ratio will therefore 
depend on the choice of dependent variable.

We have conducted a prospective study of a Faroese birth cohort, where mercury concentrations were assessed in cord blood and maternal hair at parturition, and in the child's hair and blood at the ages of 7 years and 14 years. We have now performed advanced statistical analyses to ascertain the total imprecision of these two biomarkers, the average ratio between them, and the possible concentration dependence of this ratio.

\section{MATERIALS AND METHODS}

\section{Subjects and Biomarker Assessment}

A cohort of 1022 singleton births was assembled in the Faroe Islands during a 21-month period of 1986-1987 (Grandjean et al., 1992). This North Atlantic population is of Scandinavian origin, relatively uniform, and is covered by a modern health care service. The Faroese are of particular interest in environmental epidemiology, because pilot whale is included as a traditional food item in the marine diet. Pods of this small whale species are occasionally caught and the meat and blubber are shared locally. Because of the high methylmercury concentration in the meat (Juhlshamn et al., 1987), the Faroese have a high average exposure to this contaminant and a wide range of exposure levels.

At parturition, we obtained cord blood and maternal hair for mercury analysis; a brief questionnaire included the number of dinners of pilot whale meat per month during pregnancy, alcohol use during pregnancy and the number of amalgam fillings (Grandjean et al., 1992). The full-length hair sample $(6-9 \mathrm{~cm})$ was analyzed as an indicator of the average exposure during pregnancy (Grandjean et al., 1992), and the proximal 2-cm segment from a subgroup of 683 mothers was analyzed as indicator of the recent exposure (Grandjean et al., 2003).

When the cohort members were about 7 and 14 years old, they were invited for a thorough health examination with emphasis on nervous system development. At both ages, questionnaire information was obtained about the frequency of whale meat dinners. A total of 917 of the children completed the examinations at age 7 years. A hair sample was collected from 903 of them, and the proximal segment was analyzed. Venipuncture was a voluntary part of the protocol, and a sufficient blood sample was secured from 673 children. The analytical methods have been previously described (Grandjean et al., 1997, 1999). At age 14 years, a total of 878 subjects were examined. Hair samples were obtained from 860 cohort members and the proximal segment was analyzed by atomic absorption spectrometry (Murata et al., 2003); the hair sample from a total of 104 subjects at this age showed obvious signs of dyeing or bleaching. A blood sample was obtained from 796 subjects and has now been analyzed by flow-injection cold-vapor atomic absorption spectrometry.

The total analytical imprecision (CV) for the analysis of blood at 14 years of age, not previously published, was estimated to be $17.7 \%, 5.5 \%$, and $5.8 \%$ at blood mercury concentrations of $2.2 \mu \mathrm{g} / \mathrm{l}, 8.2 \mu \mathrm{g} / \mathrm{l}$, and $13.5 \mu \mathrm{g} / \mathrm{l}$, respectively. The accuracy of the mercury determinations in blood was ensured by using Seronorm Trace Element (Sero, Norway) as quality control materials; the mercury concentrations of these samples averaged 2.2 $\mu \mathrm{g} / \mathrm{l}, 8.2 \mu \mathrm{g} / \mathrm{l}$, and $13.5 \mu \mathrm{g} / \mathrm{l}$ (assigned values $2.1 \mu \mathrm{g} / \mathrm{l}, 8.2 \mu \mathrm{g} / \mathrm{l}$, and $14.4 \mu \mathrm{g} / \mathrm{l}$, respectively). These results are similar to previous quality data. Overall, the laboratory quality results revealed an excellent accuracy and an imprecision about $5 \%$ for all biomarker determinations, though somewhat higher at low concentrations. 
Only valid pairs of mercury concentrations at each of the three examinations were used in the analysis (complete case analysis). As the simplest approach, the ratio of mercury concentrations in hair and blood was calculated for each child, and the corresponding empirical distribution was characterized by the median as well as the $5 \%-95 \%$ and $1 \%-99 \%$ ranges. In addition, we calculated the means and ranges based on a Gaussian distribution. The distribution of mercury concentrations was skewed, and a better fit of the parametric models was obtained by logarithmic transformation of the data. Differences between the hair-toblood ratios in different data sets were examined both by a paired t-test after transformation and by a signed rank non-parametric test. For comparison with previous studies by other authors, we also estimated the ratio in standard regression analysis. To determine whether known predictors of mercury exposure (Grandjean et al., 1992) affected the ratio between the two parameters, we stratified the material according to frequency of maternal whale diners, alcohol intake and number of amalgam fillings. We tested whether the ratios differed by Mann-Whitney two-sample test, Spearman rank correlation coefficient, or Kruskal-Wallis analysis of variance.

However, these approaches involve a least two problems. They do not allow estimation of the imprecision of each biomarker assessment, and they assume that the hair/blood ratio is independent of the exposure level. Structural equation models were therefore applied (Budtz-Jørgensen et al., 2002). After a logarithmic transformation, the measured concentrations in the i'th child are assumed to depend linearly on the true exposure and a random measurement error:

$$
\begin{aligned}
& \log \left(B-H g_{i}\right)=\log \left(H g_{i}\right)+\varepsilon_{b, i} \\
& \log \left(H-H g_{i}\right)=a+\beta^{*} \log \left(H g_{i}\right)+\varepsilon_{h, i}
\end{aligned}
$$

Here $\log \left(\mathrm{Hg}_{\mathrm{i}}\right)$ represents the child's true (log-transformed) exposure which is assumed to follow a Gaussian distribution. The intercept $a$ and the slope $\beta$ are unknown parameters included to avoid assuming that mercury exposures in blood and hair are on the same scale. In this case, the blood concentration is chosen as the reference indicator, and the true mercury exposure is therefore expressed on the same (log-transformed) scale as the cord blood concentration. The error functions $\varepsilon_{b, i}$ and $\varepsilon_{h, i}$ represent the total measurement errors of each of the biomarkers. These errors are assumed to be independent and to follow a Gaussian distribution with mean 0 and a variance to be estimated in the analysis.

The model assumes that the ratio is given as $\exp (a)^{*} \mathrm{Hg}^{(\beta-1)}$. Thus, the ratio is independent of the exposure level if $\beta=1$. If $\beta>1$ the hair-to-blood ratio increases at higher exposures, and if $\beta<1$ the ratio decreases. Unfortunately, this model is not identifiable because of too many unknown parameters.

This problem is solved by including the frequency of whale meat consumption as predictor of the mercury exposure (Budtz-Jørgensen et al., 2002):

$$
\log \left(\mathrm{Hg}_{\mathrm{i}}\right)=\mu+\lambda * \log \left(\text { Whale }_{\mathrm{i}}+1\right)+\varepsilon_{\mathrm{i}}
$$

Two assumptions about the association between whale meat intake and the biomarker concentrations are required to identify the unknown parameters. First, the reported whale meat intake must be correlated with the true exposure $(\lambda \neq 0)$. Second, whale meat intake must be independent of the measurement errors in the two biomarkers. The latter assumption means that, for a fixed level of the true exposure, whale meat intake must not be correlated with the biomarkers. It should be emphasized that the true exposure $\mathrm{Hg}_{i}$ is unknown and that no assumption is made whether one or another of the three parameters is more closely associated with $\mathrm{Hg}_{\text {i }}$.

The impact of outliers and influential points was then estimated to ascertain the robustness of the models. We therefore identified observations with a large absolute value of the standardized residual. The outlier limit was fixed such that the expected number of outliers in a correctly identified model would be 0.5 . With this definition, $1,4,6$, and 8 observa- 
tions were excluded from the four data sets, respectively. In addition, we examined whether sequential exclusion of influential observations affected the findings.

Meaningful comparisons of imprecision may be obtained from the calculated measurement error of each variable. However, in models where $\beta$ was different from 1 , the variances of the total measurement error of the two biomarkers would not be directly comparable because of the different measurement scales. The standard deviation for $\varepsilon_{\mathrm{h}}$ was therefore converted to the scale of the (log-transformed) blood concentration by division by $\beta$. The converted standard deviations were then compared using likelihood ratio testing. Because mercury concentrations were transformed using the natural logarithm, the error standard deviations can also be interpreted as CVs for the untransformed concentration.

Finally, it was explored whether the concentration dependence of the ratio could be explained by a ratio dependence on maternal alcohol use or maternal number of amalgam fillings. In the structural equation model, this possibility was examined by allowing for socalled item bias (Budtz-Jørgensen et al., 2002). The following equations were used:

$\log \left(B-\mathrm{Hg}_{\mathrm{i}}\right)=\log \left(\mathrm{Hg}_{\mathrm{i}}\right)+\varepsilon_{\mathrm{b}, \mathrm{i}}$ $\log \left(H-H g_{i}\right)=a+\beta * \log \left(H g_{i}\right)+y$ Alc $+\varepsilon_{h, i}$

This model allowed the hair-to-blood ratio to depend on the alcohol intake (Alc) as well as the true dose $\left(\mathrm{Hg}_{\mathrm{i}}\right)$.

\section{RESULTS}

The overall results of the mercury analyses are shown in Table 1 . The subjects covered a considerable exposure interval, as is also apparent from Figs 1 and 2. The children's postnatal exposure levels were substantially lower than the prenatal levels, and a significant increase occurred between the two most recent examinations $(p<0.001)$ (Table 1$)$. The median ratio between mercury in hair vs. cord blood was 190-200 for the two sets of maternal hair data, but postnatal ratios were clearly higher (Table 2). In particular, the hair-to-blood ratio at age 7 years was higher than the one observed at age 14 years $(p<0.0001)$. The 95th percentiles of ratios were between 5 -fold and 9-fold greater than the 5 th percentile, with the greatest variation seen in the 14-year data. Calculations assuming a Gaussian distribution of the transformed data were in excellent agreement with the non-parametric results in Table 2 (data not shown). 
Table 1. Distribution summaries of methylmercury exposure biomarkers for Faroese birth cohort members at birth and at ages 7 and 14 years.*

\begin{tabular}{lllll}
\hline Biomarker & $\mathrm{N}$ & $\begin{array}{l}\text { Geometric } \\
\text { average }\end{array}$ & $\begin{array}{l}\text { Interquartile } \\
\text { range }\end{array}$ & $\begin{array}{l}\text { Total } \\
\text { range }\end{array}$ \\
\hline $\begin{array}{l}\text { Birth } \\
\quad \text { Cord blood }(\mu \mathrm{g} / \mathrm{l})\end{array}$ & 996 & & & \\
$\quad$ Maternal hair $(\mu \mathrm{g} / \mathrm{g})$ & 22.6 & $13.1-40.5$ & $0.9-351$ \\
$\quad$ Full-length & 1019 & 4.22 & $2.52-7.66$ & $0.2-39.1$ \\
$\quad \begin{array}{l}\text { Proximal } \\
7 \text { years }\end{array}$ & 683 & 4.46 & $2.85-7.90$ & $0.3-40.5$ \\
$\quad$ Whole blood $(\mu \mathrm{g} / \mathrm{l})$ & 673 & 8.78 & $4.81-18.2$ & $0.3-62.8$ \\
$\quad$ Hair $(\mu \mathrm{g} / \mathrm{g})$ & 903 & 2.99 & $1.68-6.13$ & $0.04-37.6$ \\
$\begin{array}{l}14 \text { years } \\
\quad \text { Whole blood }(\mu \mathrm{g} / \mathrm{l})\end{array}$ & 796 & 3.81 & $2.3-7.5$ & $0.3-39.8$ \\
$\quad$ Hair $(\mu \mathrm{g} / \mathrm{g})$ & 860 & 0.96 & $0.45-2.29$ & $0.02-9.7$ \\
\hline
\end{tabular}

*Concentration data using $\mu \mathrm{g}$ may be converted to $\mathrm{nmol}$ by multiplying by 5.0 .

Table 2. Median ratio (and its distribution ranges) between mercury concentrations in hair (in $\mu \mathrm{g} / \mathrm{g}$ ) and in blood (in $\mu \mathrm{g} / \mathrm{ml}$ ) obtained from a birth cohort at three different points of time. At birth, the cord blood was compared to the maternal hair analyzed by two different methods. In addition, two sets of samples were obtained from the children at 7 and 14 years of age. These descriptive results assume a constant ratio for each data set.

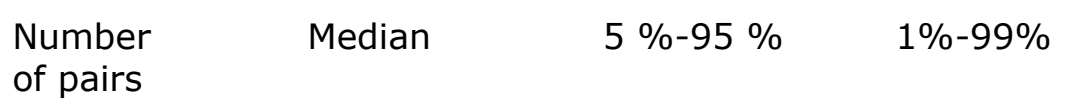

\begin{tabular}{llrrr}
\hline Birth & & & & \\
$\quad$ Full-length hair & 993 & 190 & $74-442$ & $42-680$ \\
$\quad$ Proximal hair & 666 & 201 & $89-439$ & $53-600$ \\
7 years & 665 & 370 & $137-932$ & $48-1324$ \\
14 years & 780 & 264 & $67-632$ & $18-1038$ \\
\hline
\end{tabular}



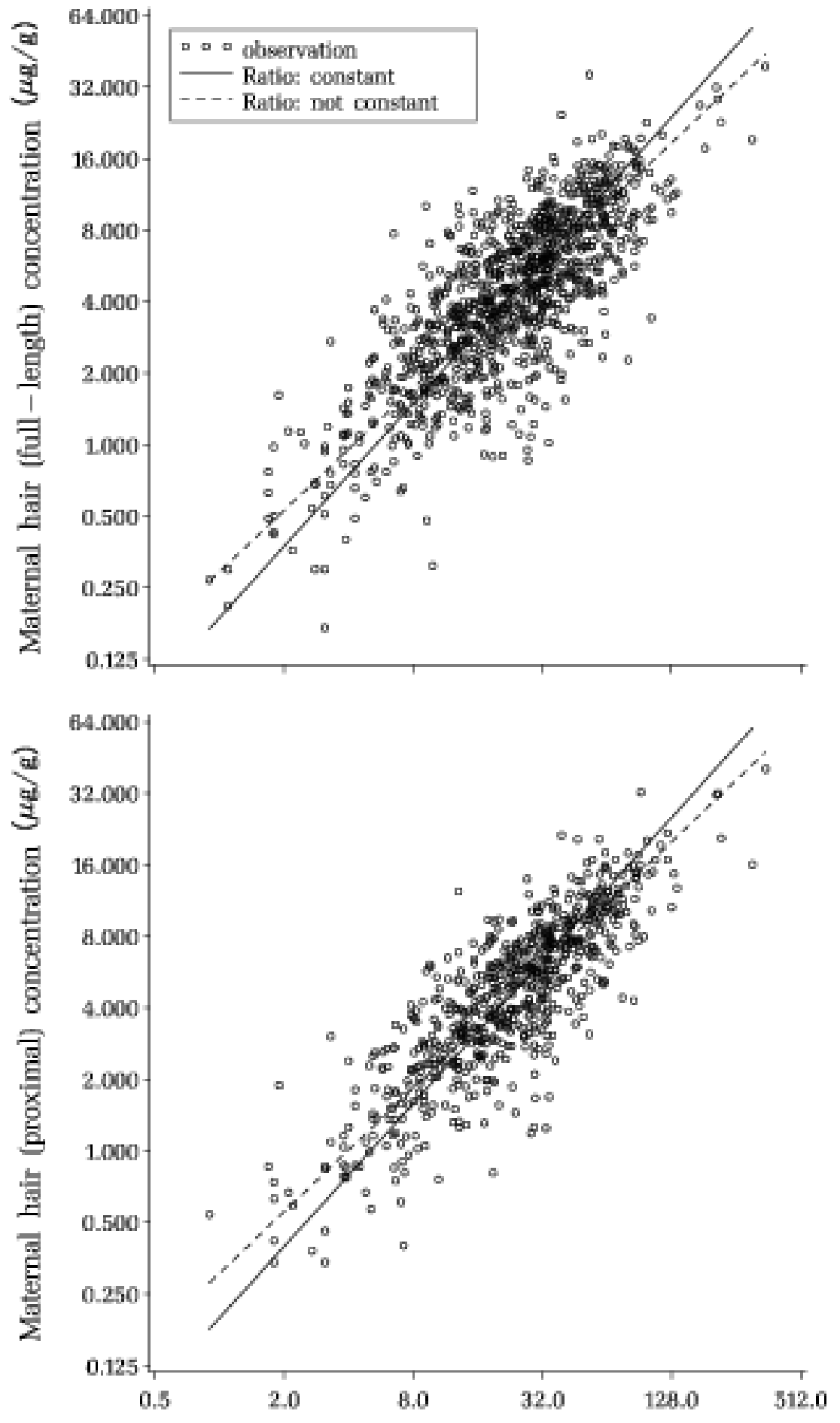

Fig. 1. Association between paired results for mercury concentrations in maternal hair $(\mu \mathrm{g} / \mathrm{g})$ and cord blood $(\mu \mathrm{g} / \mathrm{l})$ obtained from a prospective study of a Faroese birth cohort. The vertical scales show the concentration in fulllength strands (upper panel) and the proximal segment (lower panel) of the maternal hair at parturition.

Cord blood concentration $\left(\mu_{\mathrm{q}} / \mathrm{l}\right)$ 

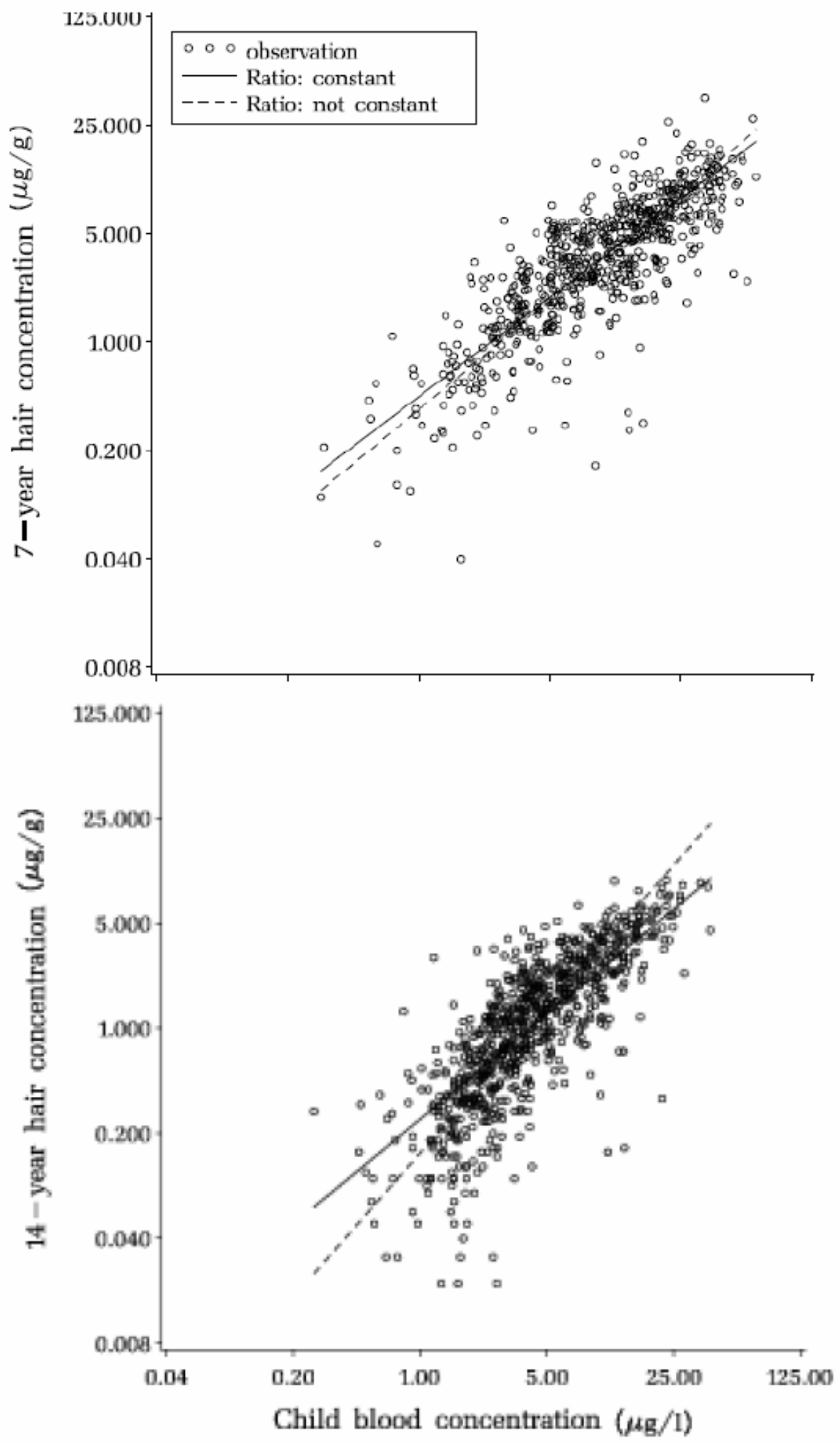

Fig. 2. Association between paired results for mercury concentrations in the child's hair $(\mu \mathrm{g} / \mathrm{g})$ and blood $(\mu \mathrm{g} / \mathrm{l})$ obtained at ages 7 years (upper panel) and 14 years (lower panel) from a prospective study of a Faroese birth cohort. 
Standard regression analysis showed a regression coefficient of 110 with mercury in full-length maternal hair as the dependent variable, and, conversely $0.0048(=1 / 208)$ for mercury in cord-blood as the dependent variable. As expected, the ratio depended on the choice of dependent variable in the regression equation. This type of analysis was therefore not further pursued.

The hair-to-blood concentration ratio was then examined in regard to predictors. This analysis was restricted to the largest data set (full-length maternal hair and cord blood), where information was available on factors that may affect methylmercury exposure (Grandjean et al., 1992). Alcohol intake (occasional vs. none) was associated with a slightly increased hair-to-blood ratio (median, 207, as compared to 187 in abstainers; Mann-Whitney test, $p=0.08$ ). The presence and number of amalgam fillings in the mother's teeth did not affect the ratio ( $p=0.30$, Spearman rank correlation). However, the ratio between mercury concentrations in hair and blood was lower if the mothers had eaten pilot whale for dinner at least twice per month during the pregnancy (median, 179), as compared to those who had eaten this food item once per month (median, 202) or not at all (median, 212) (Kruskal-Wallis test, $\mathrm{p}<0.0001$ ). A ratio difference related to whale meat intake indicates that the ratio was concentration-dependent.

Table 3. Mercury hair-to-blood ratio calculated for a child with average exposure by structural equation analysis (after exclusion of outliers). The assumption of a constant ratio ( $\beta=$ 1 ) is examined; when rejected, the hair-to-blood ratio must be adjusted for deviations from the average exposure level of the data set. The imprecision as standard deviations for the blood and hair mercury concentrations are shown, with the former also adjusted to the blood scale (Hair*).

\begin{tabular}{|c|c|c|c|c|c|c|}
\hline & \multirow[b]{2}{*}{ Ratio } & \multirow[b]{2}{*}{$\beta$} & \multirow{2}{*}{$\begin{array}{l}\mathrm{p} \text { for } \\
\text { constant ratio }\end{array}$} & \multicolumn{3}{|c|}{ Error standard deviation } \\
\hline & & & & Hair & Blood & Hair* \\
\hline \multicolumn{7}{|l|}{ Birth } \\
\hline Full-length hair & 187 & 0.857 & 0.0002 & 0.437 & 0.318 & 0.510 \\
\hline Proximal hair & 199 & 0.862 & 0.0005 & 0.351 & 0.284 & 0.407 \\
\hline 7 years & 369 & 0.914 & 0.0519 & 0.482 & 0.244 & 0.527 \\
\hline 14 years & 248 & 1.367 & $<0.0001$ & 0.493 & 0.344 & 0.360 \\
\hline
\end{tabular}

The structural equation models showed that the assumption of a constant hair-toblood ratio was not tenable, although perhaps marginally accepted for the 7-year data (Table 3). Near average exposures, the deviation from a constant ratio was small (Figs 1 and 2 ), especially in regard to the data obtained at parturition (although $\beta=1$ was likely to be rejected due to the large data sets). The largest deviation was seen at age 14 years (although this finding has to take into account the poorer fit of model). At this age the variance around the regression lines seemed greater at lower concentrations, and several subjects in the low hair-mercury range had rather high blood mercury concentrations (Fig. 2). The concentration dependence of the ratio can be expressed as the relative decrease associated with a doubling of the true exposure level $\left(1-2^{(\beta-1)}\right)$. For the data at parturition, a doubled exposure causes a reduction of the ratios for full-length and proximal maternal hair of $9.4 \%$ and $9.2 \%$, respectively. A broken regression line is included in Figs 1 and 2 to indicate the 
deviation from a constant ratio.

The concentration dependence could not be explained by maternal alcohol use or maternal number of amalgam fillings. In models that allowed the ratio to depend on these predictors and the latent exposure level, the effect of the former variables was far from significant ( $p=0.63$ and 0.27 for alcohol and amalgam fillings, respectively), while $\beta$ remained significantly different from 1.

Due to the natural logarithm transformation, the standard deviations of the error functions $\varepsilon$ obtained are equal to the CV of the untransformed variables (Table 3 ). The CV was greater for the hair-mercury concentration than for the corresponding blood value, especially in the case of maternal full-length hair $(p=0.0065)$ and 7-year hair $(p=0.0082)$. For the blood variable, the imprecision was the highest at age 14 years and similar to the one for hair-mercury (although the model fit was poorer for this data set). Overall, these total imprecisions were much greater than the known laboratory errors.

The structural equation model assumes a linear relation (with a homogeneous error) between the log-transformed mercury concentrations. For the two data sets at birth and the 7-year data, the models provided a good fit (Figs 1 and 2). For the 14-years data with the poorer fit, the impact of hair treatment was examined by excluding children with visible hair treatment. The results were only minimally affected by this exclusion, which was therefore discontinued. The fit improved after exclusion of outliers, and the estimated error variances in the biomarkers were somewhat reduced. Similar, but weaker tendencies were seen for the 7-year data, while the results at birth were not affected by outliers. Additional consideration of influential points did not change the parameter estimates markedly and was therefore not further pursued. In particular, the $\beta$ value remained stable. Thus, the concentration dependence of the hair-to-blood ratio was not caused by a few influential observations.

\section{DISCUSSION}

The present study provides new data on the reliability of exposure biomarkers routinely applied to assess environmental exposures to methylmercury. The findings suggest that the hair-mercury concentration is less precise than previously thought, that the hair-to-blood ratio is concentration dependent, and that conversion factors obtained by routine regression analysis may yield misleading results.

Conversions between hair and blood mercury concentrations are frequently applied in regard to calculating exposure limits (NRC, 2000). For example, the U.S. EPA (2001) has used an average ratio of 250. In assessing this ratio, most studies (Phelps et al., 1980; Haxton et al., 1979; Turner et al., 1980; Sherlock et al., 1982; Akagi, 1998; Bjornberg et al., 2003) have applied standard regression equations. This method erroneously includes measurement error only in the dependent variable, and the estimated conversion factor depends on the choice of dependent variable (Fuller, 1987). This problem was clearly demonstrated in the present study, where deviating results were obtained when choosing either blood or hair as dependent variable. A structural equation model allows for measurement error in both variables, as well as the possible concentration dependence of their ratio, and is therefore a more appropriate choice for estimation of the relation between the two biomarkers. This model assumes that the two mercury biomarkers are error prone manifestations of the underlying 'true' exposure level that perhaps reflects a long-term average. No assumption is made in regard to the degree of its association with any of the parameters included in the model. The dietary intake information is added in order to calibrate, and the calculation is based solely on available exposure data from each individual. The model is therefore inde- 
pendent of all other parameters available in the study, such as outcome variables and confounders, as well as any information regarding analytical and biological sources of variation.

The average hair-to-blood ratio for children at age 14 years is quite similar to the ratio of 250 used by the U.S. EPA (2001). The lower ratio for hair vs. cord blood is in accordance with the observation that mercury concentrations may be substantially higher in cord blood than in the venous blood of the mother, partly because of the higher hematocrit of the cord blood, and partly because of a greater affinity of methylmercury to fetal hemoglobin (IPCS, 1990; Stern and Smith, 2003). However, the maternal hematocrit may have decreased during pregnancy, thereby attenuating the whole-blood mercury concentration. When comparing the cord-blood based ratio of about 200 with a ratio of 250 for non-pregnant subjects, the cord-blood mercury concentration on average seems to overestimate the maternal exposure only by approximately $25 \%$. According to this calculation, benchmark dose results expressed in terms of mercury concentrations in cord blood (Budtz-Jørgensen et al., 2000; NRC, 2000) need to be multiplied by 0.8 to obtain the corresponding concentration in (non-pregnant) venous blood.

While the 14-year data are in agreement with an overall hair-to-blood ratio of about 250 for adults (U.S.EPA, 2001), the ratio obtained for the 7-year samples is significantly higher. The average blood concentration decreased between the ages of 7 and 14 years, but the decrease in hair concentrations was greater (Table 1). This observation is in accordance with the known changes in trace-element concentrations in hair during childhood (Paschal et al, 1989) and suggests that the finer hair strands at age 7 years may retain a relatively higher weight-based mercury concentration than hair at adolescence or adult ages. When comparing the hair-to-blood ratios between different data sets, the concentration dependence of the hair-to-blood ratios needs to be taken into account. Still, the difference between the calculated ratios at average mercury levels at ages 7 and 14 is far greater than would be associated with the slightly higher exposure at age 14 years.

In addition to age-dependent hair structure, other sample-specific factors may influence the hair-mercury concentration, such as the (natural) hair color (Grandjean et al., 2002). Chemical waving and straightening of hair modify the disulfide cross-links of the hair (Wolfram, 2003), and it is therefore no surprise that the mercury concentration may be substantially decreased by such treatment (Yamamoto et al., 1978; Yamaguchi et al. 2003). Henceforth, the hair-mercury concentration needs to be interpreted in the light of individual characteristics and should not be assumed to be a uniform indicator of the blood concentration or the oral exposure level. Also, based on structural differences, hair is usually categorized in three ethnic groups (i.e., African, Asian, and Caucasian) (Wolfram, 2003). Available information suggests that Asian and Caucasian hair, although structurally different, are quite similar in regard to the mercury hair-to-blood ratio (Phelps et al., 1980; Haxton et al., 1979; Turner et al., 1980; Sherlock et al., 1982; Akagi, 1998; U.S.EPA, 2001; Bjornberg et al., 2003), but African hair, although extensively studied (Cernichiari et al., 1995b), has not yet been calibrated in regard to methylmercury intakes and blood concentrations.

The concentration dependence of the ratio is difficult to explain, but could be due to several factors. This dependence was particularly obvious with the data set from the most recent examination, where the variability around the regressions lines appeared to be greater at low exposures. In several subjects, a high blood-mercury concentration at a corresponding low hair level could perhaps be explained by recent whale meat dinners that had not yet affected the proximal hair segments. Because the chemical analyses determined the total mercury concentrations, rather than individual mercury species, differences in toxicokinetic fates of mercury compounds must be considered. Thus, some inorganic mercury is known to occur in pilot whale meat (Juhlshamn et al., 1987), thereby likely adding more to the mercury concentration in blood than to that in hair. However, the effect would be a de- 
crease of the hair-to-blood ratio at low concentrations, which is counter to the tendency observed. In addition, the number of amalgam fillings, a major source of inorganic mercury exposure, did not appear to affect the ratio. Speciation of mercury in venous blood from Faroese women showed that approximately $90 \%$ of the mercury is in the form of methylmercury (Grandjean et al., 1992). In regard to cord blood, the slow passage of inorganic mercury through the placenta (Tsuchiya et al., 1984; IPCS, 1990) would suggest that this factor would not play an important role.

Among other factors that could conceivably affect the two mercury biomarkers to different extents in regard to the exposure level, analytical imprecision may be important. Most laboratory quality data suggested relatively modest and fairly constant error levels, although an increased CV was often obtained at the lowest concentration levels. A high level of quality was maintained by the experienced laboratories involved, as documented both by analysis of reference materials and participation in external quality assurance efforts (Cernichiari et al., 1995b, Grandjean et al., 2002). The validity of the data is also supported by the parallel results for the hair-mercury data at parturition (Fig. 1), despite the fact that two different laboratories conducted the two sets of analyses (Grandjean et al., 1992; Grandjean et al., 2003).

The total measurement error variance is equal to the sum of all independent sources of variance. The influence of known laboratory imprecision on the total measurement error CVs may therefore be evaluated. If, for example, the laboratory error (CV) is 5 $\%$, then a total error of $30 \%$ leaves a CV of approximately $29.6 \%$ for the preanalytical error $\left(0.05^{2}+0.296^{2}=0.3^{2}\right)$. The preanalytical variation is therefore much greater than the analytical error. Even if the laboratory error increased somewhat at low concentration levels and would be negligible at high concentrations, the impact on the total imprecision would still be minimal. This factor is therefore unlikely to explain the finding that the hair-to-blood ratio was not constant over the full range of exposures.

The known toxicokinetic fate of methylmercury suggests that the hair-mercury concentration reflects a longer-term average than the blood, particularly the full-length maternal hair that represented the complete pregnancy period (Grandjean et al., 2003). In contrast, the concentration in the cord blood represents the exposure mainly during the most recent couple of months (of gestation, in this case). Because absorbed methylmercury is detectable in hair beyond the scalp after a lag time of 1-2 months, the two biomarkers are not affected by the same biological fluctuations on a temporal scale. This notion is in agreement with the assumption of the structural equation model that total measurement errors in hair and blood are independent. Variations in exposure have been determined by analyses of sequential segments of $1-1.5 \mathrm{~cm}$ of long hair strands (Grandjean et al., 2002). Fifteen hair samples containing a mercury concentration above $10 \mu \mathrm{g} / \mathrm{g}$ mostly showed an intraindividual CV of $10-20 \%$. Thus, variations in mercury exposure levels could affect the association between exposure biomarkers that represent different time periods. However, differences in the time interval represented by the samples is unlikely to account for much of the imprecision assessed in this study, because short-term variations in exposure would be more likely to add to the imprecision for the blood sample, which was found to be less imprecise than the hair sample. Accordingly, most of the total imprecision is unexplained and must be referred to unmeasured variables, such as sample characteristics, including hair type and color, external contamination and leaching.

The variability of the hair-to-blood ratio has been used for calculation of toxicokinetic variability; distribution data on published ratios suggest that the 5 th percentile may differ from the median by a factor of about 2 (Stern et al., 2002). The present study is in agreement with this conclusion, but the increased variability at age 14 years suggests that the 5 th percentile may differ from the median by a factor of 3 . Caution should be exerted in 
considering these data, because factors other than toxicokinetic parameters appear to contribute considerably to this variability.

In concert, the four data sets indicate that the total imprecision associated with the cord-blood mercury concentration is about $30 \%$, which is much higher than the analytical imprecision alone. Under the assumptions of the model, the results also indicate that the hair-mercury concentration level is substantially more imprecise than the cord blood concentration, despite the similar high analytical quality of the laboratory analyses. The three models with an acceptable fit showed a total imprecision of about $50 \%$. These results are in accordance with previous, less extensive calculations (Budtz-Jørgensen et al., 2002; 2003).

The possible weaknesses of the structural equation model must also be considered. It assumes that the two mercury concentrations and the frequency of pilot whale intake are related to the same underlying exposure variable. Total measurement errors in the biomarkers are identified assuming that the three observed variables are independent given the latent exposure. Under these assumptions, the blood-mercury concentration was shown to be the most precise measure of the 'true' mercury exposure. However, another possible interpretation of this result is that blood and hair concentrations are measuring two different (but correlated) components of mercury exposure. In such an alternative model, the hair concentration would measure its component with an error smaller than estimated above, and the hair concentration could conceivably be a better indicator of the hair component than the blood concentration. However, the empirical observation that the hair concentration is an inferior predictor of neurobehavioral deficits at 7 years (Grandjean et al., 1999, Grandjean et al., 2003) must then be interpreted as an indication that an underlying hair component is of lesser toxicological relevance. The greater total imprecision of the hair biomarker is also in accordance with the wide variability observed when comparing hair-mercury concentrations to brain retention of mercury in deceased children (Cernichiari et al., 1995a).

In environmental epidemiological studies in general, an error-free measurement of the exposure is impossible to obtain. When an unavoidable measurement error is ignored, the estimation of the effects of the exposure is likely to be biased toward the null hypothesis (Fuller, 1987; Carroll, 1998). In interpreting epidemiological studies, specifically those based on hair-mercury assessments only, account must therefore be taken of the consequences of exposure misclassification. In addition, with the total imprecision for the exposure biomarkers being so high, laboratory efforts to improve current analytical performance alone would be unlikely to affect their validity.

\section{ACKNOWLEDGMENTS}

This study was supported by the U.S. National Institute of Environmental Health Sciences (ES09797) and the Danish Medical Research Council. The study was carried out in accordance with the Helsinki convention and with the approval of the ethical review committee for the Faroe Islands and the institutional review board in the US. We are grateful to Brita An-

dersen for conducting mercury analyses and to the children and their mothers for participating in this prospective study.

\section{REFERENCES}

Akagi, H., 1998. Studies on Mercury Pollution in the Amazon, Brazil. Global Environ. Res. 2, 
193-202.

Bjornberg, K.A., Vahter, M., Petersson-Grawe, K., Glynn, A., Cnattingius, S., Darnerud, P.O., Atuma, S., Aune, M., Becker, W., Berglund, M.. 2003. Methyl mercury and inorganic mercury in Swedish pregnant women and in cord blood: influence of fish consumption. Environ. Health Perspect. 111, 637-641.

Budtz-Jørgensen, E., Grandjean, P., Keiding, N., White, R.F., Weihe, P., 2000. Benchmark dose calculations of methylmercury-associated neurobehavioral deficits. Toxicol. Lett. 112-3, 193199.

Budtz-Jørgensen, E., Keiding, N., Grandjean, P., Weihe, P., 2002. Estimation of health effects of prenatal mercury exposure using structural equation models. Environ. Health 1, 2.

Budtz-Jørgensen, E., Keiding, N., Grandjean, P., Weihe, P., White, R.F., 2003. Consequences of exposure measurement error for confounder identification in environmental epidemiology. Stat. Med. (in press).

Carroll, R.J., 1998. Measurement error in epidemiologic studies. In: Armitage, P., Colton, T. (Eds.), Encyclopedia of biostatistics. Wiley, Chichester, pp. 2491-2519.

Cernichiari, E., Brewer, R., Myers, G.J., Marsh, D.O., Lapham, L.W., Cox, C., Shamlaye, C.F., Berlin, M., Davidson, P.W., Clarkson, T.W., 1995a. Monitoring methylmercury during pregnancy: Maternal hair predicts fetal brain exposure. Neurotoxicology 16,705-710.

Cernichiari, E., Toribara, T.Y., Liang, L., Marsh, D.O., Berlin, M., Myers, G.J., Cox, C., Shamlaye, C.F., Choisy, O., Davidson, P.W., 1995b. The biological monitoring of mercury in the Seychelles study. Neurotoxicology 16, 613-628.

Fuller, W.A., 1987. Measurement error models. Wiley, New York.

Grandjean, P., 1984. Lead poisoning: Hair analysis shows the calendar of events. Hum. Toxicol. 3, 223-8.

Grandjean, P., Budtz-Jørgensen, E., White, R.F., Jørgensen, P.J., Weihe, P., Debes, F., Keiding, N., 1999. Methylmercury exposure biomarkers as indicators of neurotoxicity in 7-year-old children. Am. J. Epidemiol. 150, 301-305.

Grandjean, P., Jørgensen, P.J., Weihe, P., 2002. Validity of mercury exposure biomarkers. In:

Wilson, S.H., Suk, W.A. (Eds.), Biomarkers of Environmentally Associated Disease. CRC

Press/Lewis, Boca Raton, pp. 235-247.

Grandjean, P., Weihe, P., Jørgensen, P.J., Clarkson, T., Cernichiari, E., Viderø, T., 1992. Impact of maternal seafood diet on fetal exposure to mercury, selenium, and lead. Arch. Environ.

Health 47, 185-195.

Grandjean, P., Weihe, P., Nielsen, J.B., 1994. Methylmercury: Significance of intrauterine and postnatal exposures. Clin. Chem. 40, 1395-1400.

Grandjean, P., Weihe, P., White, R.F., Debes, F., Araki, S., Murata, K., S! rensen, N., Dahl, D., Yokoyama, K., Jørgensen, P.J., 1997. Cognitive deficit in 7-Year-old children with prenatal exposure to methylmercury. Neurotoxicol. Teratol. 19, 417-428.

Grandjean, P., White, R.F., Weihe, P., Jørgensen, P.J., 2003. Neurotoxic risk caused by stable and variable exposure to methylmercury from seafood. Ambul. Pediatr. 3, 18-23.

Haxton, J., Lindsay, D. G., Hislop, J. S., Salmon, S., Dixon, E. J., Evans, W. H., Reid, J. R., Hewitt, C. J., Jeffries, D. F., 1979. Duplicate diet study on fishing communities in the United Kingdom: Mercury exposure in a "critical group." Environ. Res. 18, 351-368.

IPCS (International Programme on Chemical Safety), 1990. Methylmercury (Environmental Health Criteria 101). Geneva: World Health Organization.

Juhlshamn, K., Andersen, A., Ringdal, O., M! rk! re, J., 1987. Trace elements in the Faroe Islands I. Element levels in edible parts of pilot whales (Globicephalus meleanus). Sci. Tot. Environ. 65, 53-62.

Kelman, B.J., Walter, B.K., Sasser, L.B., 1982. Fetal distribution of mercury following introduction of methylmercury into porcine maternal circulation. J. Toxicol. Environ. Health 10, 191- 
200.

Montagna, W., Ellis, R.A., 1958. The Biology of Hair Growth. Academic Press, New York. Murata, K., Weihe, P., Budtz-Jørgensen, E., Jørgensen, P.J., Grandjean, P., 2003. Delayed brainstem auditory evoked potential latencies in 14-year-old children exposed to methylmercury. J. Pediatr. (in press).

NRC (National Research Council), 2000. Toxicological Effects of Methylmercury. National Academy Press, Washington.

Paschal, D.C., DiPietro, E.S., Phillips, D.L., Gunter, E.W., 1989. Age dependence of metals in hair in a selected U.S. population. Environ. Res. 48, 17-28.

Phelps, R.W., Clarkson, T.W., Kershaw, T.G., Wheatley, B., 1980. Interrelationships of blood and hair mercury concentrations in a North American population exposed to methylmercury. Arch. Environ. Health 35, 161-168.

Sherlock, J. C., Hislop, J. E., Evans, W. H., Croller, T. R., 1982. Duplication diet study on mercury intake by fish consumers in the United Kingdom. Arch. Environ. Health 37, 271-278. Smith, J.C., Farris, F.F., 1996. Methyl mercury pharmacokinetics in man: a reevaluation. Toxicol. Appl. Pharmacol. 137, 245-252.

Steigleder, G.K., Herminghaus, O., 1969. [Structure of the skin in childhood, with special reference to the sebaceous glands and hairs] Arch. Klin. Exp. Dermatol. 235, 277-283. ???

Stern, A.H., Clewell, H.J. Swartout, J., 2002. An objective uncertainty factor adjustment for methylmercury pharmacokinetic variability. Hum. Ecol. Risk Assessm. 8, 885-894.

Stern, A.H., Smith, A.E., 2003. An assessment of the cord blood:maternal blood methylmercury ratio: implications for risk assessment. Environ. Health Perspect. 111, 1465-1470.

Steuerwald, U., Weihe, P., Jørgensen, P.J., Bjerve, K., Brock, J., Heinzow, B., Budtz-Jørgensen, E., Grandjean, P., 2000. Maternal seafood diet, methylmercury exposure, and neonatal neurological function. J. Pediatr. 136, 599-605.

Suzuki, T., 1988. Hair and nails: advantages and pitfalls when used in biological monitoring. In: Clarkson, T.W., Friberg, L., Nordberg, G.F., Sager, P.R. (Eds.), Biological Monitoring of Toxic Metals. Plenum, New York, pp. 623-640.

Tsuchiya, H., Mitani, K., Kodama, K., Nakata, T., 1984. Placental transfer of heavy metals in normal pregnant Japanese women. Arch. Environ. Health 39, 11-17.

Turner, M.D., Marsh, D.O., Smith, J.C., Inglis, J.B., Clarkson, T.W., Rubio, C.E., Chiriboga, J., Chiriboga, C.C., 1980. Methylmercury in populations eating large quantities of marine fish.

Arch. Environ. Health 35, 367-378.

U.S. EPA (Environmental Protection Agency), 2001. Water Quality Criterion for the Protection of Human Health: Methylmercury, Final. EPA-823-R-01-001. Washington. URL: http://www.epa.gov/waterscience/criteria/methylmercury/document.html (accessed, August 15, 2003)

Wolfram, L.J., 2003. Human hair: a unique physicochemical composite. J. Am. Acad. Dermatol. 48, S106-14.

Yamaguchi, S., Matsumoto, H., Kaku, S., Tateishi, M., Shiramizu, M., 1975. Factors affecting the amount of mercury in human scalp hair. Am. J. Publ. Health 65, 484-8.

Yamamoto R, Suzuki T., 1978. Effects of artificial hair-waving on hair mercury values. Int.

Arch. Occup. Environ. Health 42, 1-9.

Yasutake, A., Matsumoto, M., Yamaguchi, M., Hachiya, N., 2003. Current Hair Mercury Levels in Japanese: Survey in Five Districts. Tohoku J. Exp. Med. 199, 161-169. 